\title{
Primary and Secondary Control Strategies for Managing Health and Financial Stress Across Adulthood
}

\author{
Carsten Wrosch and Jutta Heckhausen \\ Max Planck Institute for Human Development
}

\author{
Margie E. Lachman \\ Brandeis University
}

\begin{abstract}
The study examined the relation among three types of control strategies (persistence, positive reappraisals, lowering aspirations) and subjective well-being across adulthood $(N=3,490)$. Specifically, the authors investigated whether age-adapted endorsement of control strategies is conducive to subjective well-being if individuals experience health or financial stress. The results reveal an overall enhanced reliance on control strategies in older as compared with younger adults. In addition, persistence showed a stronger positive relation to subjective well-being in young adulthood as compared with old age. In midlife and old age, positive reappraisals had a stronger positive relation to subjective well-being than persistence. Lowering aspirations was negatively related to subjective well-being, independent of age. Age differences in the relation of control strategies to subjective well-being were particularly salient in individuals who faced either health or financial stress.
\end{abstract}

This study addressed the endorsement and predictive value of individuals' control strategies across the lifespan. Specifically, we examined age differences in the relation between control strategies and subjective well-being. Moreover, we investigated whether age-adapted investment of control strategies is particularly beneficial for individuals who face specific types of stressors (health stress and financial stress). We proposed that individuals' endorsement of primary and secondary control is functionally tailored to age-graded constraints and opportunities for development. Primary control strategies are directed at attaining personal goals and overcoming obstacles (Heckhausen \& Schulz, 1995; Rothbaum, Weisz, \& Snyder, 1982). Primary control strategies should thus be most efficient at younger ages when life-course related opportunities are favorable for a wide range of developmental pathways. At older ages, by contrast, individuals have less control over intended outcomes of behavior; the opportunities for goal attainment in many domains (e.g., health, career, family) have become sharply reduced. Therefore, we proposed that in older adults selfprotective secondary control (e.g., positive reappraisals) is more necessary and thus predictive of successful development. Finally, we hypothesized that age differences in the effectiveness of control

Carsten Wrosch and Jutta Heckhausen, Max Planck Institute for Human Development, Berlin, Germany; Margie E. Lachman, Department of Psychology, Brandeis University.

This research was supported by the John D. and Catherine T. MacArthur Foundation Research Network on Successful Midlife Development, Orville Gilbert Brim, Chair. Part of this article was written during a visit of Carsten Wrosch to the University of Pittsburgh, University Center for Social and Urban Research.

We thank Karen Z. H. Li and Lynn M. Martire for valuable comments on drafts of this article.

Correspondence concerning this article should be addressed to Carsten Wrosch, who is now at Department of Psychology, Carnegie Mellon University, Pittsburgh, Pennsylvania 15213. Electronic mail may be sent to wrosch $+@$ andrew.cmu.edu. strategies would be particularly apparent in those individuals who face concrete challenges that involve age-related opportunity structures, such as managing health and financial problems.

\section{Health- and Finance-Related Challenges Across the Life Course}

Individuals have to negotiate a number of developmental tasks across their life course (e.g., Erikson, 1968; Havighurst, 1953). The age-graded scaffolding of developmental tasks (Sørensen, 1990) has been described as a well structured "time table" (e.g., Hagestad, 1990) that provides the individual with information about the best timing for the attainment of developmental goals (Heckhausen, 1999). In general, the specific timing of developmental goals depends on the age-related impact of biological, sociostructural, and age-normative factors (e.g., Baltes \& Baltes, 1980). The opportunities for attaining various developmental goals (e.g., establishing a partnership or a career) are very favorable in young adulthood. With advancing age, individuals become more concerned with managing losses and maintaining levels of functioning, although gains and losses are present in any period of life (e.g., Baltes, 1987; Heckhausen, Dixon, \& Baltes, 1989). Moreover, the achievement of goals that are easily attainable in young adulthood may be obstructed in old age, because the age-graded structure of the life course provides fewer opportunities and more constraints for development (Brandtstädter \& Renner, 1990; Heckhausen \& Schulz, 1995).

Across the life course, financial and health-related goals show contrasting trajectories (Cross \& Markus, 1991; Heckhausen, 1997; Nurmi, 1992). Based on the age-graded structure of the life course, the favorable opportunities for goal attainment support and canalize the striving for financial goals in young and middle adulthood. Health-related goals, by contrast, become more apparent in older ages, when individuals are vulnerable to chronic diseases and face loss in cognitive functioning (e.g., Baltes, 1987; Brock, Guralnick, \& Brody, 1990). Problems and stress in health 
and finances should be particularly frequent during the time period associated with developmental tasks in the respective domain, that is striving for advanced career goals in young adulthood and early midlife, and mastering the beginning physical decline in later midlife. Thus, individuals presumably experience financial stress more frequently in young and middle adulthood when they attempt to develop and maintain a career. Health stress should be more prevalent in older ages because the individual is confronting an increasing number of acute and chronic diseases. Nonetheless, individuals of all ages also face events and problems that are normatively less expected (nonnormative events; Baltes, Cornelius, \& Nesselroade, 1979). In addition, the recent deregulation of the life course (e.g., Held, 1986) might have contributed to a situation in which deviations from normative transitions and events occur more frequently and affect more individuals. Thus, it can be expected that, independent of age, a proportion of individuals experience health and financial problems, even if it is agenormatively less expected (e.g., health stress in young adulthood).

In general, stress challenges the individuals' regulatory system and requires the activation of control processes for managing the problem (Aldwin, Sutton, \& Lachman, 1996; Lazarus \& Folkman, 1984), although the experience of stress does not necessarily imply that individuals intend to manage the respective problems. In particular, serious health problems such as major illnesses can directly affect other ongoing goal pursuits. Giving up health goals might undermine the fundamental resource of control (e.g., Schulz \& Heckhausen, 1996). Similarly, financial problems can be expected to negatively influence individuals' personal development across a broad range of life domains, such as family development, leisure activities, and lifestyle. With respect to both health and finances, the controllability for managing problems and stress in the respective domain is expected to decline with advancing age. Health problems become less controllable with increasing physical decline, decreasing personal resources, and the onset of chronic diseases in old age (e.g., Schulz, Heckhausen, \& O'Brien, 1994). Similarly, managing financial stress might become more difficult when individuals retire and therefore may have fewer opportunities to manage financial problems by investing personal resources. Thus, the investment of age-appropriate control strategies might play a crucial role in determining adaptive and maladaptive adjustment and development.

\section{Developmental Regulation in Primary and Secondary Control}

Theories about control behavior typically assume that individuals actively regulate their development (e.g., Carver \& Scheier, 1982; Heckhausen \& Schulz, 1995; Lachman \& Burack, 1993; Lerner \& Busch-Rossnagel, 1981; Skinner, 1995). Individuals select goals, strive for their attainment, and manage the consequences resulting from failure and loss (Heckhausen, 1999). Recent conceptualizations of control behavior have distinguished between primary and secondary control processes (Heckhausen \& Schulz, 1993, 1995; Rothbaum, Weisz, \& Snyder, 1982; Schulz \& Heckhausen, 1996). Primary control striving refers to individuals' attempts to change the external world so that it fits with their personal needs and desires. Typical examples of primary control striving are persistence in goal striving or the investment of time and effort if obstacles emerge. Secondary control striving, by contrast, is targeted at the inner world and involves individuals' efforts to influence their own motivation, emotion, and mental representation (Rothbaum et al., 1982). Exemplar processes of secondary control include positive reappraisal, downward comparison, attributional bias, or goal disengagement.

Heckhausen and Schulz (1993, 1995; Schulz \& Heckhausen, 1996) developed a life-span theory of control that proposes specific age trajectories for primary control potential, primary control striving, and secondary control striving. The ability to bring about outcomes, that is, primary control potential, is expected to increase during early childhood and adolescence, to remain stable across adulthood, and to decline in old age (Heckhausen \& Schulz, 1995). By contrast, individuals' striving for primary control should remain stable across the entire life span, so that individuals are motivated to produce behavior-event contingencies throughout their lives (e.g., White, 1959). Compensatory secondary control ${ }^{1}$ striving is expected to develop in middle childhood and then to increase across the entire life span (Heckhausen \& Schulz, 1993, 1995). An extended use of compensatory secondary control with advancing age should help the individual to compensate for failure and developmental losses that are more frequently experienced in older ages.

The endorsement and the adaptive function of primary versus compensatory secondary control strategies depend on the respective opportunity structures for goal attainment (Heckhausen, 1999; Wrosch \& Heckhausen, 1999). Favorable opportunities for goal attainment should prompt the individual to invest in primary control. Unfavorable opportunity structures, by contrast, should elicit enhanced compensatory secondary control striving. Overall, both primary and secondary control strategies are adaptive in so far as they enhance and protect individuals' resources for managing prospective development by using strategies of goal attainment, self-protective mechanisms, and processes of disengaging from, and rescaling of, futile goals (e.g., primacy of primary control; Heckhausen \& Schulz, 1995, 1999).

In this study, we examined the endorsement and effect of three types of control strategies that prototypically represent primary and secondary control striving. With regard to primary control, we investigated persistence in goal striving. Persistence in goal striving can be seen as a core component of primary control striving, conceptually comparable to constructs such as selective primary control (Heckhausen \& Schulz, 1993) or tenacious goal pursuit (Brandtstädter \& Renner, 1990). Persistence in goal striving should be particularly adaptive in young adulthood when opportunities for goal attainment are favorable. With regard to secondary control, we addressed two strategies that represent theoretically derived and empirically supported subcomponents of the construct (e.g., self-protection and goal disengagement; Wrosch \& Heckhausen, 1999). First, we investigated the secondary control strategy of positive reappraisals (e.g., seeing the positive side of a bad situation). The function of this type of strategy is to protect

\footnotetext{
${ }^{1}$ Heckhausen and Schulz (1993) distinguished between selective and compensatory secondary control strategies. Selective secondary control is related to enhancing the volitional commitment toward a goal and therefore support goal attainment. In this study we only investigated compensatory secondary control, which is related to psychological compensation after experiencing failure and loss.
} 
individuals' motivational and emotional resources after experiencing failure or developmental losses. Positive reappraisals should become increasingly important with advancing age if the opportunities for goal attainment decline. Second, we examined the secondary control strategy of lowering aspirations (e.g., Brandtstädter \& Rothermund, 1994; Brim, 1992). This strategy is related to goal disengagement and rescaling goals. Goal disengagement is expected to result from negative life events and should be particularly maladaptive if the individual faces favorable opportunities for goal attainment. Moreover, goal disengagement from essential life domains, such as health and finances, would have detrimental effects on the individual's overall control resources. However, goal disengagement could be adaptive in the long run if people disengage from goals with sharply reduced opportunity structures without undermining their control potential in essential domains of life.

A number of empirical studies have confirmed age-differential endorsement of primary and secondary control strategies. With respect to compensatory secondary control, cross-sectional studies provide convergent evidence that older, as compared with younger, adults more frequently use strategies associated with compensatory secondary control (Heckhausen, Schulz, \& Wrosch, 1998; Peng, 1993; Wrosch \& Heckhausen, 1999) and related constructs such as accommodation (Brandtstädter \& Renner, 1990; Brandtstädter, Wentura, \& Greve, 1993; Heckhausen, 1997) and emotion-focused coping (Folkman, Lazarus, Pimley, \& Novacek, 1987; Quayhagen \& Quayhagen, 1982). In contrast, the empirical evidence with respect to age differences in primary control is inconsistent. Cross-sectional studies have shown an age-graded increase (Heckhausen et al., 1998), stability (Heckhausen, 1997; Peng, 1993; Peng \& Lachman, 1994), and decrease (Brandtstädter \& Renner, 1990; Brandtstädter et al., 1993) in strategies associated with primary control (e.g., assimilation, problem-focused coping). Possible explanations for these conflicting findings might relate to self-selected and nonrepresentative samples as well as to differences in the constructs and empirical indicators used.

With respect to the predictive relations of control strategies, empirical studies have confirmed positive correlations between both primary and self-protective secondary control strategies and indicators of successful development, such as life satisfaction, low depression, perceived control, and subjective well-being (e.g., Brandtstädter \& Renner, 1990; Heckhausen et al,, 1998). Age comparative studies about the predictive relations of control strategies to indicators of successful development are scarce. Peng (1993) examined the relation between both primary and secondary control strategies and psychological well-being across adulthood. In young adulthood, secondary control was negatively related to self-acceptance, purpose in life, autonomy, and environmental mastery. For older adults, by contrast, secondary control showed positive correlations with personal growth and positive relations with others (Peng, 1993). In addition, Wrosch and Heckhausen (1999) investigated control processes of recently separated individuals in young adulthood and late midlife. The results showed that older, as compared with younger, separated individuals perceived reduced opportunities for forming a new intimate partnership and reported higher ratings in compensatory secondary control. Moreover, the investment of compensatory secondary control was positively related to longitudinal improvement of emotional well-being in older separated participants, whereas younger sepa- rated adults suffered decline in positive affect if they endorsed high levels of compensatory secondary control (Wrosch \& Heckhausen, 1999). Overall, the reported studies provide some initial evidence that an age-adapted use of control strategies is conducive to high levels of subjective well-being.

\section{Present Research and Predictions}

The study addressed the influence of control strategies on subjective well-being by examining the age-related relevance of three prototypical types of control processes: (a) persistence in goal striving (primary control), (b) positive reappraisals (self-protective secondary control), and (c) lowering aspirations (secondary control related to goal adjustment). Our general assumption was that control strategies serve different functions across the life course, depending on the age-graded opportunities and constraints for goal attainment. In younger ages, individuals face favorable opportunities for goal attainment. In contrast, the opportiunities for attaining a number of developmental goals become sharply reduced with increasing age. To illustrate the adaptive value of age-related endorsement of control strategies in two life domains, we also examined individuals who were faced with high versus low levels of perceived health and financial problems.

The study's hypotheses are divided into three sets described below. First, we expected age differences in the endorsement of control strategies. The second set of hypotheses addressed age differences in the predictive value of primary and secondary control for participants' well-being. In the third set of hypotheses, we predicted that an age-adapted endorsement of control strategies would be particularly conducive to high levels of well-being when individuals experience health stress and financial stress.

\section{Age Differences in the Endorsement of Control Strategies}

On the basis of the theoretical framework described above, we expected age differences in the investment of control strategies. Specifically, we hypothesized age-related increases in both types of secondary control strategies, positive reappraisals and lowering aspirations. Positive reappraisals and lowering aspirations were expected to increase in older individuals as a consequence of increasing developmental losses and decreasing opportunity structures for goal attainment. With respect to primary control by persistence, we hypothesized stability across age, based on the assumption that people of all ages are motivated to produce behavior-event contingencies.

\section{Predictive Value of Control Strategies Across Adulthood}

Assuming that the opportunities for attaining personal goals decrease with age, we hypothesized that persistence in goal striving (primary control) has a stronger positive impact on subjective well-being in young adulthood as compared with old age. Positive reappraisals (secondary control), by contrast, should be increasingly beneficial with advancing age. The adaptive role of lowering aspirations (secondary control) is characterized by disengaging from futile goals, rescaling unrealistic intentions, and redirecting resources to other life domains. However, disengagement from personal goals should be associated with experiences of failure and loss. Therefore, we expected that secondary control by lowering 
aspirations would show negative relationships with subjective well-being.

\section{Managing Health and Financial Stress}

We proposed that the expected age-specific effects of control strategies on subjective well-being should be particularly related to individuals facing health or financial stress. The latter hypothesis is based on two assumptions: First, stress-related situations are a challenge for individuals' self-regulation, and, therefore, individual differences in the endorsement of control strategies should be more closely related to managing the respective problem and subsequently to subjective well-being. Second, both health and financial stresses are expected to be less controllable in old age as compared with young adulthood. Thus, directly comparing younger and older individuals who are challenged with managing problems might lend further support to our hypotheses of an opportunity-related impact of the investment of control strategies on subjective well-being.

\section{Method}

\section{Participants}

The data for this study were collected by the John D. and Catherine T. MacArthur Foundation Network on Successful Midlife Development in 1995. The survey (Midlife in the United States [MIDUS]) was based on a national probability sample of English-speaking and noninstitutionalized adults from households in the United States. Participants were selected with random digit dialing procedures. The study included a telephone interview lasting approximately $30 \mathrm{~min}$. In addition, questionnaires were mailed to the participants. In order to maximize response rates, an extensive procedure consisting of phone calls, letters, and incentives was implemented.

The telephone sample included 4,242 respondents; their ages ranged from 25 to 76 years $(M=48.85, S D=13.21)$. Fifty-eight percent of the sample were men. With respect to education, $11 \%$ had less than a high school diploma, $27 \%$ had completed high school, $30 \%$ had completed some college, and $31 \%$ had attained a baccalaureate or advanced degree. The majority of the sample was Caucasian $(88 \%)$. Eighty-seven percent of respondents $(3,690)$ returned the questionnaires. For the reported study, we included only participants $(3,490)$ who provided ratings for control strategies, health stress, financial stress, and subjective well-being. Participants whose data were used in the analyses were comparable to the participants of the telephone sample with respect to age $(M=48.77, S D=13.16)$, gender ( $50 \% \mathrm{men})$, race ( $88 \%$ Caucasian), and education $(10 \%$ less than high school, $27 \%$ high school, 30 some college, $33 \%$ baccalaureate or advanced degree)

\section{Instruments}

The constructs used in this study were participants' ratings of reported control strategies, health stress, financial stress, subjective well-being, and sociodemographic characteristics (age, gender, education, race).

Control strategies. We measured control strategies with a 14-item instrument using a 4-point Likert scale $(1=$ not at all, $4=a$ lot ; developed from Peng \& Lachman, 1994). Participants indicated how well the items described them. An exploratory factor analyses confirmed our theoretically derived three-factor model. We labeled the three scales of control strategies as "persistence in goal striving (primary control)" (Cronbach's $\alpha=.77$; eigenvalue $=1.14$ ), "positive reappraisals (secondary control)" (Cronbach's $\alpha=.78$; eigenvalue $=4.13$ ), and "lowering aspirations (secondary control)" (Cronbach's $\alpha=.63$; eigenvalue $=2.04$ ). The specific items are documented in the Appendix. To provide evidence for the validity of the three scales, we performed zero-order correlations with generalized control beliefs (mastery; e.g., Lachman \& Weaver, 1998a; Pearlin \& Schooler, 1978). Both, persistence $(r=.47, p<.01)$ and positive reappraisals $(r=$ $.39, p<.01$ ) showed positive correlations with mastery beliefs, whereas lowering aspirations was negatively correlated with mastery beliefs $(r=$ $-.20, p<.01)^{2}$

Health and financial stress. We measured health stress by using a symptom checklist of health problems experienced during the past 12 months. Participants were requested to report whether they had experienced each of 28 health symptoms (e.g., asthma, tuberculosis, AIDS, heart attack, diabetes, or multiple sclerosis). The mean number of reported health problems was $2.29(S D=2.39)$. We measured financial stress by using two items. Participants were requested to report whether they (a) had enough money to meet their needs and (b) had difficulties in paying the monthly bills. Financial problems were indicated if the participants either reported not having enough money to meet their needs or if they reported that it is somewhat or very difficult to pay their monthly bills. On average, participants reported $.66(S D=.82)$ financial problems.

Subjective well-being. To measure subjective well-being, we used a composite score (factor score). The subjective well-being measure consisted of participants' ratings about (a) present life overall (11-point scale; $0=$ worst, $10=$ best), (b) present life satisfaction (4-point scale; $1=$ not at all, $4=$ a lot ), (c) satisfaction with self (4-point scale; $1=$ not at all, $4=$ a lot), (d) worry about life (5-point scale; $1=$ a lot more than most other people, 5 = less than most other people), and (e) disappointment about achievements in life (6-point scale; 1 = strongly disagree, $6=$ strongly agree). A more positive score indicated higher levels of subjective wellbeing. For the current sample, the items of the scale showed a Cronbach's alpha of 65 .

\section{Analytic Procedures}

We investigated mean differences in the endorsement of control strategies as well as in self-reports of health and financial stress by using analysis of variance (ANOVA) procedures. Because of the large sample size, we report only those main effects that were significant at $p<.01$. To identify the specific age group differences, we conducted follow-up analyses $(p<.05)$. We included gender, education level, and race in the analyses to examine whether these factors influenced the results.

In order to estimate the predictive value of control strategies on subjective well-being, we used multiple-group structural modeling analyses (using LISREL; Jöreskog \& Sörbom, 1989, 1993). We examined differences in the predictive value of control strategies for subjective well-being by using three model types: (a) a main effect model including the entire sample, (b) a multiple age-group model, and (c) two Multiple AgeGroup $\times$ Multiple Stress Group (health and financial stress) models.

On the basis of an exploratory factor analysis that confirmed the hypothesized three-factor model of control strategies, we parceled the items (e.g., Kishton \& Widaman, 1994) of each control construct into three manifest indicators for measuring (a) persistence in goal striving (out of five items), (b) positive reappraisals (out of four items), and (c) lowering aspirations (out of five items). Using three indicators has been shown to be an optimal strategy for identifying a latent construct (e.g., three-indicator rule; Bollen, 1989b). In addition, the parceling technique might correct for unreliability of single items (Kishton \& Widaman, 1994). For each control construct, the correlations among the three parcels were significant at $p<$ .01 and ranged between $r=.36$ and $r=.70$. We represented the outcome

\footnotetext{
${ }^{2}$ Additional evidence concerning the validity of the measures are reported in Peng's (1993) dissertation. Some of these results (e.g., relation to psychological well-being) are also mentioned in the body of the manuscript (see p. 8).
} 
measure of subjective well-being by a single indicator that was calculated as a composite score in factor analysis. All models included participants' gender, education level (two levels: less than college, college and higher), and race (three levels: Caucasian, African American, other) as covariates. We assessed model fit using the nonnormed fit index (NNFI; Bentler \& Bonett, 1980), the incremental fit index (IFI; Bollen, 1989a), and the root mean squared error of approximation (RMSEA; Browne \& Cudeck, 1993). The overall model that predicted the main effects of control strategy endorsement on subjective well-being revealed acceptable fit statistics $\left[\chi^{2}(68, N=3,490)=585.21, \mathrm{NNFI}=.94, \mathrm{IFI}=.96, \mathrm{RMSEA}<.05\right]$.

To examine differences in the predictive relations of control strategies across groups, we divided the participants into different groups based on their age, health stress, and financial stress. Participants were grouped with respect to young adulthood (age range $=25-39$ ), midlife (age range $=$ $40-59$ ), and old age (age range $=60-76$ ). In addition, participants were grouped into those with low versus high health stress (less than two vs. two or more health problems) and financial stress (none vs. one or two financial problems). To satisfy the requirements of a multiple group structural equation modeling approach, the cut-off points for the stress groups were chosen to obtain reliable covariance matrices by classifying a sufficient number of participants into the different groups. With respect to age, the groups consisted of 1,013 young adults $(61 \%$ low health stress, $39 \%$ high health stress; $47 \%$ low financial stress, $53 \%$ high financial stress); 1,650 middle-aged adults ( $46 \%$ low health stress, $54 \%$ high health stress; $55 \%$ low financial stress, $45 \%$ high financial stress); and 827 older adults ( $31 \%$ low health stress, $69 \%$ high health stress; $73 \%$ low financial stress, $27 \%$ high financial stress). We assessed acceptable fit indices for the age-group model, $\chi^{2}(204, N=3,490)=963.33, \mathrm{NNFI}=.92, \mathrm{IFI}=.94$, RMSEA $=$ .06 ; the Age Group $\times$ Health Stress model, $\chi^{2}(408, N=3,490)=1389.78$, NNFI $=.90$, IFI $=.93$, RMSEA $=.06$; and the Age Group $\times$ Financial Stress model, $\chi^{2}(408, N=3,490)=870.41$, NNFI $=.95$, IFI $=.96$, RMSEA $=.04$.

Before examining the predictive relations of control strategies on subjective well-being, we tested the measurement invariance (constraining the factor loading across groups to be equal) as well as structural invariance (constraining the factor variances across groups to be equal) across groups. Invariance of constructs can be seen as an essential validity condition for exploring hypothesized structural differences in latent constructs across groups (Little, 1997). In regard to the overall fit indices, we found strong support for measurement invariance of the constructs across age groups, $\chi^{2}(216, N=3,490)=980.88$, NNFI $=.93$, IFI $=.94$, RMSEA $=.05 ;$ Age Groups $\times$ Health Stress Groups, $\chi^{2}(438, N=3,490)=1430.82$, NNFI $=$ .91 , IFI $=.92$, RMSEA $=.06$; and Age Groups $\times$ Financial Stress Groups, $\chi^{2}(438, N=3,490)=917.81$, NNFI $=.95$, IFI $=.96$, RMSEA $=.04 . \mathrm{A}$ direct comparison of the models revealed no significant differences in regard to the age group model, $\Delta \chi^{2}=17.01, \Delta d f=12, p>.10$, and the Age Group $\times$ Health Stress model, $\Delta \chi^{2}=41.04, \Delta d f=30, p>.05$, but a small significant difference for the Age Group $\times$ Financial Stress model, $\Delta \chi^{2}=47.40, \Delta d f=30, p>.02$. To test for structural invariance, we then constrained the variances of the constructs to be equal across groups. The analyses showed a decrease of the fit statistics: age group model, $\chi^{2}(232$, $N=3,490)=13331.96, \mathrm{NNFI}=.90, \mathrm{IFI}=.92, \mathrm{RMSEA}=.06 ;$ Age Group $\times$ Health Stress model, $\chi^{2}(478, N=3,490)=1862.65$, NNFI $=$ .88 , IFI $=.90$, RMSEA $=.07$; and Age Group $\times$ Financial Stress model, $\chi^{2}(478, N=3,490)=1610.60, \mathrm{NNFI}=.90, \mathrm{IFI}=.91, \mathrm{RMSEA}=.06$. In addition, structural invariance was not supported if calculating direct $\chi^{2}$-difference tests (age group model: $\Delta \chi^{2}=352.08, \Delta d f=16, p<.01$; Age Group $\times$ Health Stress model: $\Delta \chi^{2}=431.83, \Delta d f=40, p<.01$; Age Group $\times$ Financial Stress model: $\Delta \chi^{2}=692.79, \Delta d f=40, p<.01$ ). These results indicate that we presumably measured comparable constructs across groups but variances of the latent constructs, however, differ across groups. Following Little (1997), we decomposed the latent covariances into variances and correlations by introducing yoked phantom variates (secondorder factors) into the models. This procedure allows one to represent group differences in construct variances as group differences in the loadings of the second-order factors (for a more detailed description, see Little, 1997). Therefore, it is very unlikely that differences in variances across groups affect group differences found in the structural relations between constructs (e.g., beta paths). We examined group differences in the predictive relations of control strategies as follows. First, we compared significant with nonsignificant beta-paths. Second, we placed cross-groups equality constraints on the beta-paths. We then evaluated the difference in model fit for significance (criterion: $p<.05$ ).

\section{Results}

\section{Endorsement of Control Strategies Across Adulthood}

We examined mean differences in the endorsement of control strategies according to the same groups that we studied in the structural modeling approach (age group, health stress, financial stress). In addition, we controlled for participants' gender, education, and race. Thus, we conducted a 3 (type of control strategy) $\times 3$ (age group) $\times 2$ (health stress) $\times 2$ (financial stress) ANOVA with "type of strategy" as a within-subject factor. We found a significant main effect for age group, $F(2,3478)=15.62$, $p<.01, \eta^{2}=.009$. Moreover, we obtained a significant interaction for "type of strategy," $F(2,6956)=2357.42, p<.01, \eta^{2}=$ .404 , and significant interactions involving type of strategy [by health stress, $F(2,6956)=26.87, p<.01, \eta^{2}=.008$; by financial stress, $F(2,6956)=28.56, p<.01, \eta^{2}=.008$ ]. Because of these significant interactions, we conducted separate ANOVAs for each strategy.

The significant group effects of the ANOVAs are reported in Table 1. We obtained significant age-group effects for persistence in goal striving (primary control) and lowering aspirations (secondary control) at $p<.01$, as well as for positive reappraisals (secondary control) at $p=.05$. Posttest analyses showed as pre-

Table I

Significant Effects of ANOVAs Investigating Group Differences in Participants' Control Strategies, Health Problems, and Financial Problems

\begin{tabular}{lrrr}
\hline \multicolumn{1}{c}{ Significant group effect } & $F^{\mathrm{a}}$ & \multicolumn{1}{c}{$p$} & $\eta^{2}$ \\
\hline Persistence in goal striving (primary control) & & & \\
$\quad$ Age group & 6.64 & .001 & .004 \\
Health stress & 22.31 & .000 & .006 \\
$\quad$ Financial stress & 18.03 & .006 & .005 \\
Positive reappraisals (secondary control) & & & \\
$\quad$ Age group & 2.95 & .052 & .002 \\
$\quad$ Financial stress & 11.31 & .001 & .003 \\
Lowering aspirations (secondary control) & & & \\
Age group & 15.71 & .000 & .009 \\
Health stress & 20.55 & .000 & .006 \\
Financial stress & 22.13 & .000 & .006 \\
Health problems & & & \\
$\quad$ Age group & 81.21 & .000 & .044 \\
Gender & 37.15 & .000 & .011 \\
$\quad$ Education level & 14.57 & .000 & .004 \\
Financial problems & & & \\
$\quad$ Age group & 71.19 & .000 & .039 \\
Gender & 21.58 & .000 & .006 \\
Education level & 30.25 & .000 & .009 \\
\hline
\end{tabular}

Note. ANOVA $=$ analysis of variance.

${ }^{a}$ The $d f s$ for age-group effects are 2 and 3478 ; all other $d f s$ are 1 and 3478 . 
dicted that older adults reported higher endorsement of lowering aspirations than did participants in young adulthood and midlife (see Table 2; all comparisons between age groups were significant at $p<.05$ ). Contrary to our predictions, however, we found that older participants reported greater persistence than the younger age groups (see Table 2; all comparisons between age groups were significant at $p<.05$ ). Moreover, Table 2 shows as predicted that younger participants reported lower ratings in positive reappraisals than participants in middle adulthood, $t(2661)=-2.26, p=.02$, and old age, $t(1838)=-2.43, p=.02$. Middle-aged and older adults did not differ statistically in positive reappraisals.

Moreover, we found significant health stress effects for persistence and lowering aspirations (see Table 1). Participants who reported high as compared with low health stress showed lower ratings in persistence (high: $M=3.20, S D=.55$; low: $M=3.29$, $S D=.53$ ) and higher ratings in lowering aspirations (high: $M=2.36, S D=.57$; low: $M=2.23, S D=.57$ ). Participants who perceived financial stress reported lower levels of persistence $(M=3.18, S D=.56)$ and positive reappraisals $(M=3.10, S D=$ $.62)$ and higher levels of lowering aspirations $(M=2.35, S D=$ .58 ) than respondents who reported no financial stress (persistence: $M=3.29, S D=.52$; positive reappraisals: $M=3.19, S D=.59$; lowering aspirations: $M=2.26, S D=.57$ ). We did not find significant interaction effects between age and reported stressors for participants' endorsement of control strategies.

All effects remained significant if controlling for participants' gender, education, and race. Gender, $F(1,3477)=93.14, p<.01$, $\eta^{2}=.026$, and educational level, $F(1,3477)=29.89, p<.01$, $\eta^{2}=.009$, showed significant effects on lowering aspirations. Women $(M=2.40, S D=.56)$ as well as less educated participants $(M=2.39, S D=.61)$ reported higher ratings in lowering aspirations than men $(M=2.20, S D=.58)$ and more educated respondents $(M=2.25, S D=.55)$. Race was shown to be related to persistence, $F(2,3476)=9.16, p<.01, \eta^{2}=.005$, and positive reappraisals, $F(2,3476)=6.98, p<.01, \eta^{2}=.004$. Caucasians reported lower ratings in persistence $(M=3.23, S D=.54)$ and positive reappraisals ( $M=3.14, S D=.60$ ) as compared with African Americans [persistence: $M=3.36, S D=.52 ; t(3291)=$
$-3.39, p<.01$; positive reappraisals: $M=3.27, S D=.57$; $t(3291)=-2.96, p<.01]$.

\section{Predictive Relations of Control Strategies to Subjective Well-Being Across Adulthood}

To investigate differences in the predictive value of control strategies for subjective well-being across age groups, we examined two different models: a main effect model and a three-age group model. All models controlled for gender, educational level, and race. The disattenuated correlations between constructs used in the structural modeling approach are reported in Table 3. Participants' age was included in the analyses to validate the results of the ANOVA approach. Congruent with the ANOVA approach, age was positively related to all three types of control strategies as well as to reported health problems, but negatively related to perceived financial problems. Moreover, subjective well-being significantly increased with age (see Table 3 ). In addition, it should be noted that persistence in goal striving showed a relatively strong correlation with positive reappraisals.

The main effect model that predicted subjective well-being by the endorsement of control striving (controlling for gender, education, and race) showed significant beta paths for all three types of control strategies. Persistence in goal striving (primary control; $\beta=.13, p<.01$ ) as well as positive reappraisals (secondary control; $\beta=.28, p<.01$ ) showed positive effects on subjective well-being, whereas lowering aspirations (secondary control; $\beta=$ $-.21, p<.01$ ) was negatively related to subjective well-being. Moreover, specific comparisons revealed that the unique effect of positive reappraisals on subjective well-being was stronger than the unique effect of persistence on subjective well-being, $\Delta \chi^{2}=6.16, \Delta d f=1, p=.01$. Altogether, the three control strategies accounted for $17 \%$ of the variance in subjective well-being.

Figure 1 shows the predictive relations of control strategies on subjective well-being in the three age groups. The analysis revealed that the enhanced effect of positive reappraisals (secondary control) over persistence (primary control) on subjective well-

Table 2

Means (and Standard Deviations) of Participants' Control Strategies, Health Problems, and Financial Problems for the Total Sample and for Different Age Groups

\begin{tabular}{|c|c|c|c|c|}
\hline \multirow[b]{2}{*}{ Construct } & \multirow[b]{2}{*}{$\begin{array}{l}\text { Total } \\
\text { sample }\end{array}$} & \multicolumn{3}{|c|}{ Age groups } \\
\hline & & $\begin{array}{c}\text { Young } \\
\text { adulthood } \\
\text { (age 25-39) }\end{array}$ & $\begin{array}{c}\text { Middle } \\
\text { adulthood } \\
\text { (age } 40-59 \text { ) }\end{array}$ & $\begin{array}{c}\text { Older } \\
\text { adulthood } \\
\text { (age } 60-76 \text { ) }\end{array}$ \\
\hline \multicolumn{5}{|l|}{ Control strategies } \\
\hline Persistence & $3.24(0.54)$ & $3.20(0.54)^{\mathrm{a}}$ & $3.24(0.55)$ & $3.30(0.54)$ \\
\hline Positive reappraisals & $3.15(0.60)$ & $3.11(0.61)^{\mathrm{b}}$ & $3.16(0.60)$ & $3.18(0.59)$ \\
\hline $\begin{array}{l}\text { Lowering } \\
\text { aspirations }\end{array}$ & $2.30(0.58)$ & $2.23(0.55)^{\mathrm{a}}$ & $2.29(0.57)$ & $2.40(0.60)$ \\
\hline \multicolumn{5}{|l|}{ Reported problems } \\
\hline $\begin{array}{l}\text { Health } \\
\text { (Range) }\end{array}$ & $\begin{array}{r}2.29(2.39) \\
(0-25)\end{array}$ & $\begin{array}{c}1.59(1.88)^{\mathrm{a}} \\
(0-15)\end{array}$ & $\begin{array}{r}2.33(2.39) \\
(0-19)\end{array}$ & $\begin{array}{r}3.07(2.66) \\
(0-25)\end{array}$ \\
\hline $\begin{array}{l}\text { Finances } \\
\quad \text { (Range) }\end{array}$ & $\begin{array}{c}.66(0.82) \\
(0-2)\end{array}$ & $\begin{array}{c}.81(0.84)^{\mathrm{b}} \\
(0-2)\end{array}$ & $\begin{array}{c}.69(0.83) \\
(0-2)\end{array}$ & $\begin{array}{c}.39(0.70) \\
(0-2)\end{array}$ \\
\hline
\end{tabular}

a All age groups significantly differ from each other, $p<.05$. ${ }^{\mathrm{b}}$ Significantly differs from other age groups, $p<$ .05 . 
Table 3

Disattenuated Zero-Order Correlations Between Constructs Used in the Structural Equation Modeling Analyses

\begin{tabular}{|c|c|c|c|c|c|c|c|}
\hline Construct & 1 & 2 & 3 & 4 & 5 & 6 & 7 \\
\hline 1. Persistence & - & & & & & & \\
\hline 2. Positive reappraisals & .69 & - & & & & & \\
\hline 3. Lowering aspirations & -.14 & $-.03 \uparrow$ & - & & & & \\
\hline 4. Health stress & -.09 & -.07 & .18 & - & & & \\
\hline 5. Financial stress & -.12 & -.08 & .10 & .14 & - & & \\
\hline 6. Subjective well-being & .32 & .34 & -.24 & -.27 & -.32 & - & \\
\hline 7. $\mathrm{Age}^{\mathrm{a}}$ & .10 & .06 & .14 & .25 & -.18 & .08 & - \\
\hline
\end{tabular}

a Correlations with age were additionally presented to validate the analysis of variance results.

$\dagger$ Not significant; all other correlations are significant at $p<.01$.

being was only found for middle-aged adults, $\Delta \chi^{2}=5.72$, $\Delta d f=1, p<.02$, and older adults, $\Delta \chi^{2}=4.26, \Delta d f=1, p<.04$; no significant differences were obtained for participants in young adulthood. Persistence in goal striving showed no significant effect on subjective well-being in older adults; whereas its effect was significantly stronger in young adults, $\Delta \chi^{2}=3.75, \Delta d f=1, p=$ .05 , and significant in middle-aged adults. The proportions of variance explained in subjective well-being by the three control constructs ranged from $21 \%$ in middle-aged adults to $12 \%$ in older adults (16\% in young adults).

\section{Managing Health Stress and Financial Stress Across Adulthood}

Before testing our hypotheses of the relevance of age-adapted control processes for managing health and financial stress, we examined the distributions of health stress and financial stress across different groups. Therefore, we performed separate 3 (age group) $\times 2$ (gender) $\times 2$ (educational level) ANOVAs for health stress and financial stress. With respect to both perceived health and financial stress, Table 1 shows that we found significant main

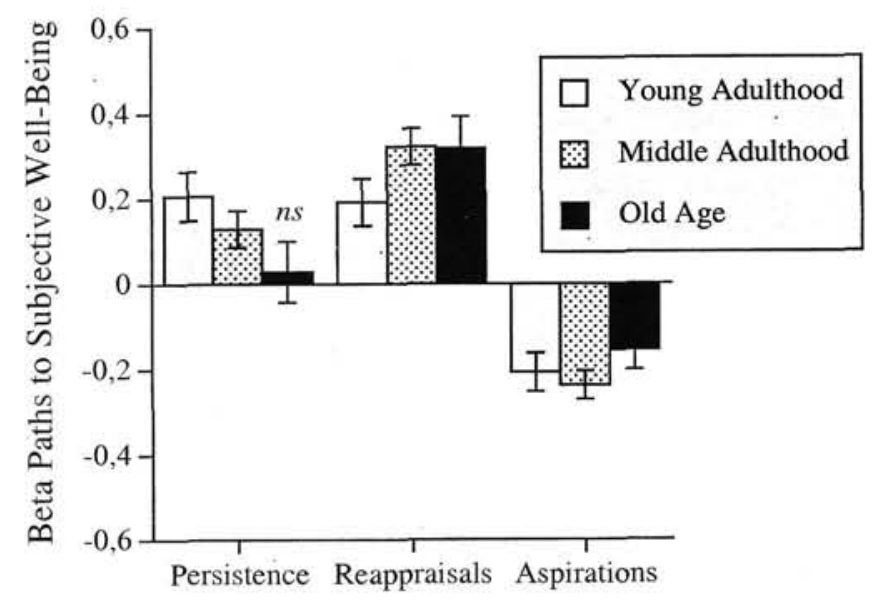

Control Strategies

Figure 1. Control strategies as predictors of subjective well-being in young, middle-aged, and older adults. All beta paths are significant at $p<$ .01 , except for one marked as $n s$. effects for age group, gender, and education level. Follow-up analyses ( $t$ tests) revealed that health stress was more frequently experienced in older as compared with younger ages, whereas financial stress was more frequently reported by younger as compared with older participants (see Table 2; all age group comparisons were significant at $p<.05$; all $t \mathrm{~s}>3.45$ ). Women (health: $M=2.57, S D=2.51$; finances: $M=.72, S D=.85$ ) reported more health and financial stress than men (health: $M=2.01, S D=2.22$; finances: $M=.59, S D=.79$ ). In addition, less educated participants (health: $M=2.61, S D=2.62$; finances: $M=.74, S D=.83$ ) reported more health and financial problems than more educated participants (health: $M=2.11, S D=2.22$; finances: $M=.61$, $S D=.81$ ). The results remained stable when controlling for participants' race. However, race showed a significant effect on financial stress, $F(1,3476)=14.22, p<.01, \eta^{2}=.008$, with less stress reported by Caucasians $(M=.62, S D=.81)$ as compared with African Americans $(M=.95, S D=.89 ; t[237.16]=-5.19$, $p<.01)$ and others $(M=.83, S D=.84 ; t[3275]=-3.49$, $p=.02$ ).

To obtain more specific information for interpreting the age differences found in reported health stress, we conducted additional analyses for participants of the high health stress group. We examined whether the three most frequently mentioned health problems differed by age group. The analyses showed that participants' most frequently mentioned health problems significantly differed across age groups, all $\chi^{2} \mathrm{~s}>5.91$, all $p s \leq .05$. As expected, health problems seem to be more chronic and thus presumably less controllable in older as compared with younger adults. Of the older participants, 50\% reported arthritis, $44 \%$ hypertension, and $35 \%$ sciatica. The most frequently mentioned health problems in middle adulthood were sciatica (36\%), arthritis $(34 \%)$, and stomach problems $(34 \%)$. Young adults, in contrast, mentioned stomach problems $(42 \%)$, hay fever $(34 \%)$, and sciatica $(29 \%)$.

\section{Age Differences in the Adaptive Value of Control Strategies Across High and Low Stress Groups}

To examine age differences in the predictive value of control strategies on subjective well-being in participants of high- and low-stress groups, we tested a 3 (age group) $\times 2$ (health stress group) model (Figure 2, upper panel) and a 3 (age group) $\times 2$ (financial stress group) model (Figure 2, lower panel). The find- 

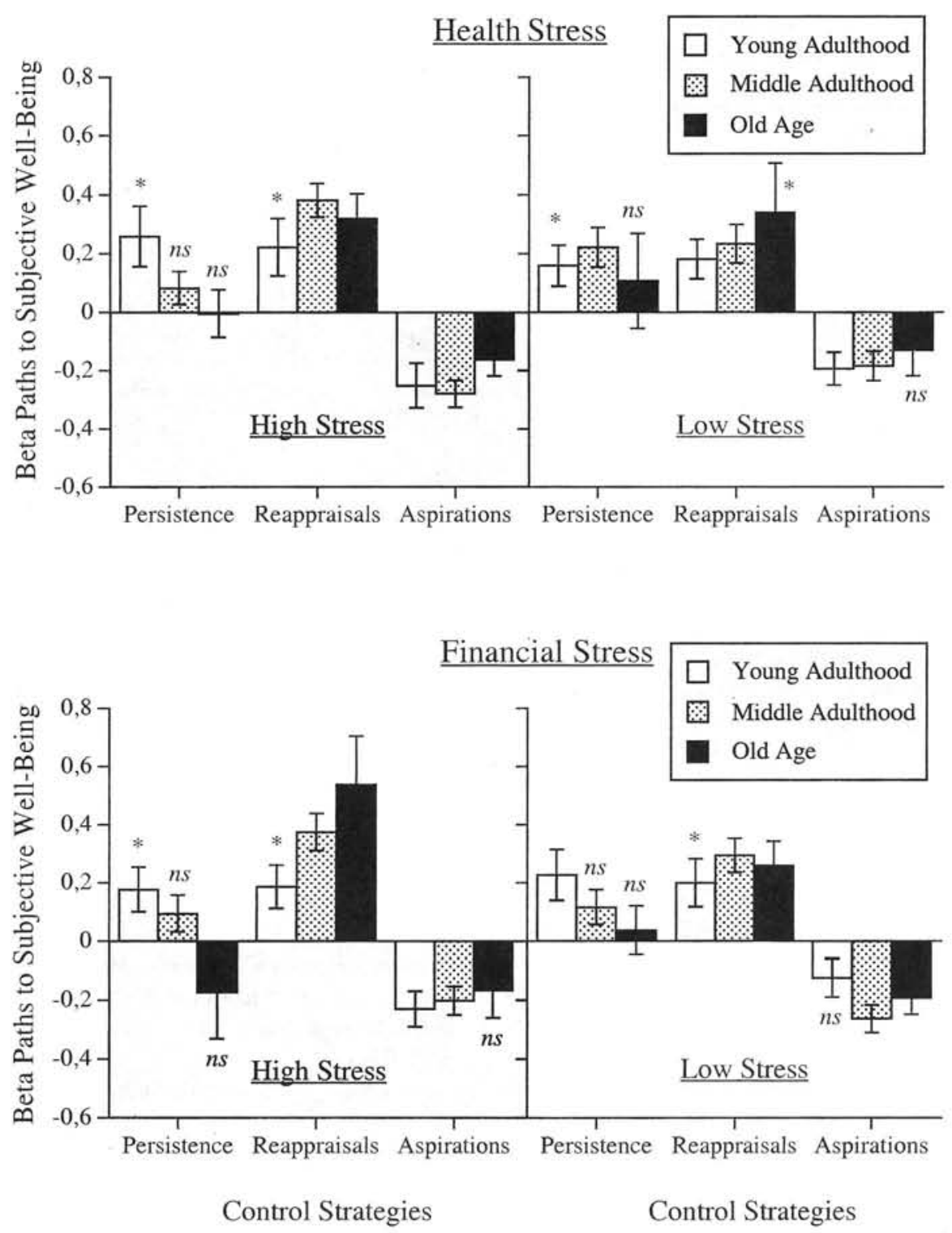

Figure 2. Control strategies as predictors of subjective well-being in young, middle-aged, and older adults experiencing high versus low levels of health stress (upper panel) and financial stress (lower panel). All beta paths are significant at $p<.01$, except those marked with an $*(p<.05)$ and with $n s$.

ings showed that the age differences for predicting subjective well-being were related to whether participants experienced health or financial stress. Positive reappraisals (secondary control) as compared with persistence (primary control) showed stronger effects on subjective well-being in middle-aged and older participants, but only if the participants reported either health stress (middle-aged adults: $\Delta \chi^{2}=8.07, \Delta d f=1, p<.01$; older adults: $\Delta \chi^{2}=4.30, \Delta d f=1, p<.04$ ) or financial stress (middle-aged adults: $\Delta \chi^{2}=5.60, \Delta d f=1, p<.02$; older adults: $\Delta \chi^{2}=5.67$, $\Delta d f=1, p<.02$ ). For younger participants, no significant differences between the predictive value of persistence and positive reappraisals on subjective well-being were found, regardless of the stress-level group.

In accordance with the age-group model, the impact of persistence on subjective well-being was lower in older adults as com- pared with young adults, but only for participants who reported either health stress, $\Delta \chi^{2}=4.03, \Delta d f=1, p<.05$, or financial stress, $\Delta \chi^{2}=4.95, \Delta d f=1, p<.05$. In addition, the analyses revealed that for participants who perceived high financial stress, positive reappraisals showed a stronger unique effect in older as compared with young adults, $\Delta \chi^{2}=3.75, \Delta d f=1, p=.05$. Moreover, it should be noted that lowering aspirations showed generally negative effects on subjective well-being, except for older adults who perceived either high levels of financial stress or low levels of health stress.

The proportions of variance in subjective well-being explained by participants' endorsement of control strategies ranged from $11 \%$ to $22 \%$. Most interesting was that the impact of control strategies on subjective well-being was almost twice as high in younger adults who reported health stress $(22 \%)$ as compared with 
younger adults who reported less health stress $(13 \%)$ and older adults who experienced health stress (11\%). Moreover, it should be noted that control strategies shared a large amount of variance with subjective well-being in middle-aged adults, independently of whether they experienced health and financial stress or not (between $19 \%$ and $22 \%)^{3}$

\section{Discussion}

The present study examined the endorsement and predictive value of control strategies on subjective well-being in a life-span context. The basic theoretical assumption was that the investment of control strategies would be functionally tailored to the agegraded requirements in developmental regulation. In younger ages, the opportunities for attaining a number of developmental goals are favorable. With advancing age, however, opportunities for goal attainment are continuously reduced. We expected an age-adapted endorsement of primary and secondary control strategies to relate to high levels of subjective well-being. In addition, we proposed that the hypothesized age-related endorsement of control strategies would be most closely related to high levels of subjective wellbeing if individuals face financial or health-related stress.

\section{Age-Graded Endorsement of Control Strategies}

According to our hypotheses, we found age differences in the endorsement of primary and secondary control strategies. As expected, older adults reported higher levels of secondary control strategies than younger adults. This was shown with respect to both indicators of secondary control, positive reappraisals and lowering aspirations. The enhanced endorsement of secondary control strategies by older adults presumably reflects an adaptation to the age-related increase of developmental losses (by lowering aspirations) as well as individuals' attempts to protect their emotional and motivational resources (by positive reappraisals). In contrast, we found no support for age-related stability in primary control by persistence. Older people also reported higher ratings in primary control by persistence than younger participants. These results are congruent with findings reported by Heckhausen et al. (1998), who argued that an enhanced reliance of older adults on control strategies might well reflect the greater challenges for developmental regulation. Older people might be challenged to compensate for age-related declines in objective control potential by investing more primary control. This way, older individuals may still attain important goals by investing greater effort and resources. Such developmental challenges are particularly likely at "young" old age. For a concluding discussion, however, it seems relevant to first integrate the age differences found in the mean values of control strategies with the age differences in the predictive value of control strategies.

\section{Predictive Value of Control Strategies Across the Life Course}

The reported results strongly support the hypothesis of agegrading in the predictive value of control strategies. With respect to participants' subjective well-being, primary control striving (persistence) was shown to be an adaptive mechanism particularly in young adulthood and midlife, but did not predict subjective well-being in older adults. The endorsement of self-protective secondary control (positive reappraisals) as compared with primary control had a stronger impact on subjective well-being in middle-aged and older adults. Lowering aspirations, by contrast, was negatively related to subjective well-being, independent of participants' age. By considering the decreasing opportunity structures with increasing age (Baltes, 1987; Heckhausen, 1999; Heckhausen \& Schulz, 1995), it can be assumed that primary control striving is less effective for goal attainment in older as compared with younger adults and therefore, less related to subjective wellbeing. Instead, with advancing age self-protective secondary control striving becomes more important for regulating well-being.

Integrating age differences found in the mean level of control strategies and age differences obtained in the predictive value of control strategies leads to an interesting pattern of findings. The study's findings indicate an age-related increase in the mean levels of both persistence in goal striving (primary control) and positive reappraisals (secondary control), but indicate contrasting age effects of persistence (negative relation) and positive reappraisal (positive relation) on subjective well-being. With respect to positive reappraisals, the results indicate that self-protective control strategies become increasingly important in old age when the developmental ecology provides fewer opportunities for goal attainment. Thus, investing more self-protective secondary control can be interpreted as an appropriate strategy for older adults. As mentioned above, the reported finding that older people also invest more primary control striving (persistence) than younger people may imply that older people attempt to compensate for declines in objective control potential. Considering the age-decreasing effectiveness of primary control, older people seem to intensify their primary control attempts, presumably in well-selected life domains in which maintaining a certain amount of control is still possible. This age-related pattern of endorsement of control processes converges with the finding that participants' well-being did not decrease across age, but instead showed a slightly positive correlation (for a meta-analysis, see Stock, Okun, Haring, \& Witter, 1983).

\section{Managing Health and Financial Stress Across the Life Course}

The age-graded structure of developmental tasks across the life course (Erikson, 1968; Havighurst, 1953) provides contrasting developmental trajectories for health and financial stress. We found more pronounced health-related stress in older adults, whereas individuals in young adulthood and midlife reported financial stress most frequently. Nonetheless, a smaller but considerable number of individuals reported problems that would be age-normatively less expected (e.g., health problems in young adulthood). In addition, the analyses showed that older, as compared with younger, adults mentioned chronic health problems more frequently (e.g., arthritis, hypertension). Although we know little about the objective control potential of these diseases, we assume that chronic as compared with nonchronic health problems

\footnotetext{
${ }^{3}$ In the remaining participant groups, the endorsement of control strategies explained between $15 \%$ and $16 \%$ of subjective well-being, except for older participants who reported low financial stress $(11 \%)$.
} 
involve fewer opportunities for realizing health goals (e.g., attaining perfect health). Thus, the results support our assumption that health-related stress management involves age-graded opportunity structures. The age-graded opportunities for managing financial stress, in contrast, were not directly measured. However, we assumed that older individuals who are more frequently retired (56\%) than young adults $(0.4 \%)$ and middle-aged adults $(5 \%)$ might have fewer opportunities to manage financial problems by investment of personal resources.

With regard to our hypotheses based on the life-span theory of control, the findings revealed that an age-adapted investment of control strategies is conducive to successful development if individuals experience health and financial stress. For both high-stress groups, an age-related decrease of the predictive value of primary control (persistence) on subjective well-being was found. Moreover, self-protective secondary control (positive reappraisals) as compared with persistence was more strongly related to subjective well-being in middle-aged and older adults. This pattern of results was only obtained in participants who reported either high health or financial stress. It should be considered, however, that having the burden of problems has different effects on age-normative trajectories (age-related increase of health stress and decrease of financial stress). In addition, reported health stress shared only a small proportion of variance with reported financial stress. Thus, we presumably extracted different subsamples into the groups of high-stress participants.

Overall, we assume that the generalized control strategies show meaningful predictive effects for participants who perceived either health stress or financial stress because such strategies reflect, at least partly, the management of participants' relevant problems and goals. In particular, the age-related opportunity structures for managing goals and problems of the respective life domain might determine the adaptive value of control strategies used. Individuals who experience stress and endorse control strategies that are tailored to the age-graded opportunities and constraints of the life course profit most in terms of subjective well-being. Moreover, by considering the greater endorsement of self-protective strategies in old age, these findings may contribute to research showing that perceived control over finances and health does not decrease across age (e.g., Lachman \& Weaver, 1998b). In sum, the findings support our hypothesis that an age-adapted endorsement of control strategies becomes particularly important if individuals confront problems that involve age-differential opportunities for goal attainment.

The proportions of variance in subjective well-being explained by the three types of control strategies ranged from $11 \%$ to $22 \%$. The results showed that the endorsement of control strategies explained almost twice as much variance in subjective well-being if younger adults were confronted with health stress $(22 \%)$ as compared with older adults who reported high levels of health stress $(11 \%)$ and younger adults who reported less health stress $(13 \%)$. Thus, individual differences in preferred control strategies seem to be most influential in young adults who experience health stress. However, beyond the more favorable opportunities and higher controllability for managing health stress in young adulthood as compared with old age, there might be an additional reason. In view of the fact that health stress is a less normative event in young adulthood, one might assume that societal support (e.g., Brandtstädter, 1990; Schulz \& Rau, 1985) and peer support (e.g., Brim \& Ryff, 1980) is less available for young adults who experience health stress. Thus, individual differences in motivational processes, such as control striving, might have a greater impact on attaining health goals and subsequently on subjective well-being. Moreover, participants' control strategies explained relatively large proportions of variance $(19 \%$ to $22 \%$ ) in subjective well-being in middle-aged adults, independently of whether they experienced stress. Midlife, as a period of life where people face various responsibilities and challenges (e.g., children, job; see Lachman \& James, 1997) more than they do in other life periods, requires well-adapted control processes (Heckhausen, in press).

\section{Limitations}

Although this study investigated the influence of control strategies on subjective well-being in a national probability sample, a number of limitations should be addressed. Our theoretical model proposes causal effects of individuals' endorsement of control strategies on subjective well-being. The cross-sectional and quasiexperimental (high- vs. low-stress groups) design, however, does not allow testing the causal nature of effects. Therefore, other interpretations of the reported findings might hold too. Those participants, for example, who are more satisfied might be more motivated to manage health or financial stress and therefore may use well-adapted control strategies more frequently. Thus, gaining control might also be conceptualized as an outcome of individuals' experience and behavior. With regard to the cross-sectional design of the study, it seems relevant to note that process-oriented approaches of coping and control have argued for changes of selfregulatory processes during the course of problem management and action regulation (e.g., Brandtstädter \& Renner, 1990; Gollwitzer, Heckhausen, \& Steller, 1990; Lazarus, 1996). We can not exclude that some of our findings might pertain to individuals who are in different stages of problem management. However, by considering the way items were phrased we can assume that the reported problems were experienced during the past 12 months, supporting the conclusion that systematic stage-related variation between participants of different age groups is relatively unlikely. However, longitudinal research is needed to explore the causal nature of processes and effects.

Another relevant issue relates to the theoretical status of the control constructs used. In particular, the relatively high correlation between persistence in goal striving and positive reappraisals raises questions with regard to the proposed differential function of control strategies. We assume that the generalized control constructs used in this study cover processes of development regulation across a wider range of life domains. Therefore, generalized control constructs might show positive intercorrelations, because individuals presumably use different control strategies for regulating different goals. Moreover, individuals might use different control strategies for managing a given goal or problem. Thus, positive correlations between constructs might not invalidate our interpretations. In addition, the method used (e.g., regression coefficients) controls for the predictive relations of different control strategies. We would expect that domain-specific measures of control strategies show a more pronounced pattern of results. In fact, research on managing partnership goals has confirmed that domain-specific as compared with generalized control constructs 
more closely reflect age-graded opportunity structures for goal attainment (e.g., Wrosch \& Heckhausen, 1999).

Finally, it should be mentioned that our study had a restricted age range and did not investigate very old people ( 80 years and older). It may be possible that, for instance, self-protective secondary control strategies lose their adaptive function for maintaining subjective well-being in very old people, if levels of functioning decline below a certain threshold and therefore, adaptation to developmental losses as well as creating sense in life might become increasingly difficult (Schulz, Heckhausen, \& O'Brien, 1994).

\section{Summary and Conclusions}

The reported study confirmed the hypothesis of age-differential effects of individuals' control striving on subjective well-being. Primary control striving (persistence) was shown to have beneficial effects on subjective well-being particularly in younger adults. Self-protective secondary control strategies (positive reappraisal) as compared with primary control were more strongly related to subjective well-being in middle-aged and older adults. Secondary control by lowering aspirations and giving up goals was negatively related to subjective well-being, independent of individuals' age. Moreover, this age-graded pattern only pertained to individuals who experienced high levels of health or financial stress. Therefore, it can be concluded that the endorsement of control strategies that is adaptively tailored to the requirements of the life course is highly beneficial for managing problems that involve age-related opportunity structures for goal attainment. Primary control striving is most adaptive if individuals face favorable opportunities for development and managing stress in young adulthood. Selfprotective compensatory control, by contrast, becomes increasingly important for stabilizing individuals' well-being if the opportunities for goal attainment decrease with advancing age.

Finally, we found that older, as compared with younger, adults not only reported an increased reliance on secondary control strategies but also on primary control. Individuals in old age may attempt to compensate for the loss in efficiency of persistent goal striving not only by using self-protective secondary control strategies but also by investing more primary control resources.

Future research might contribute to a more profound understanding of the impact of individuals' control processes for managing stress and successful development. It seems useful to extend the analyses by including problems experienced in other domains of life, such as family or partnership. Moreover, the specific processes as well as their causal directions should be studied in longitudinal analyses. Thus, a process-oriented approach would help to illuminate the complex relations between individuals" control behavior and its consequences for subjective well-being throughout life.

\section{References}

Aldwin, C. M., Sutton, K. J., \& Lachman, M. E. (1996). The development of coping resources in adulthood. Joumal of Personality, 64, 837-871.

Baltes, P. B. (1987). Theoretical propositions of life-span developmental psychology: On the dynamics between growth and decline. Developmental Psychology, 23, 611-626.

Baltes, P. B., \& Baltes, M. M. (1980). Plasticity and variability in psychological aging: Methodological and theoretical issues. In G. E. Gurski
(Ed.), Determining the effects of aging on the central nervous system (pp. 41-66). Berlin, Germany: Schering.

Baltes, P. B., Comelius, S. W., \& Nesselroade, J. R. (1979). Cohort effects in developmental psychology. In J. R. Nesselroade \& P. B. Baltes (Eds.), Longitudinal research in the study of behavior and development (pp. 61-87). New York: Academic Press.

Bentler, P. M., \& Bonett, D. G. (1980). Significance tests and goodness of fit in the analyses of covariance structures. Psychological Bulletin, 107, $238-246$.

Bollen, K. A. (1989a). A new incremental fit index for general structural equation models. Sociological Methods and Research, 17, 303-316.

Bollen, K. A. (1989b). Structural equations with latent variables. New York: Wiley.

Brandtstädter, J. (1990). Entwicklung im Lebenslauf: Ansätze und Probleme der Lebensspannen-Entwicklungspsychologie [Development across the life course: Approaches and problems of life-span psychology]. Kölner Zeitschrift für Soziologie und Sozialpsychologie, Sonderheft 31 , 322-350.

Brandtstädter, J., \& Renner, G. (1990). Tenacious goal pursuit and flexible goal adjustment: Explication and age-related analysis of assimilative and accommodative strategies of coping. Psychology and Aging, 5, 58-67.

Brandtstädter, J., \& Rothermund, K. (1994). Self-percepts of control in middle and later adulthood: Buffering losses by rescaling goals. Psychology and Aging, 9, 265-273.

Brandtstădter, J., Wentura, D., \& Greve, W. (1993). Adaptive resources of the aging self: Outlines of an emergent perspective. Intemational Journal of Behavioral Development, 16, 323-349.

Brim, O. G. (1992). Ambition: How we manage success and failure throughout our lives. New York: Basic Books.

Brim, O. G., \& Ryff, C. D. (1980). On the properties of life events. In P. B. Baltes \& O. G. Brim, Jr. (Eds.), Life-span development and behavior (Vol. 3, pp. 367-388). New York: Academic Press.

Brock, D. B., Guralnick, J. M., \& Brody, J. A. (1990). Demography and epidemiology of aging in the United States. In E. L. Schneider \& J. W. Rowe (Eds.), Handbook of the biology of aging (3rd ed., pp. 3-23). New York: Academic Press.

Browne, M. W., \& Cudeck, R. (1993). Alternative ways of assessing model fit. In K. A. Bollen \& J. S. Long (Eds.), Testing structural equation models (pp. 136-162). Newbury Park, CA: Sage.

Carver, S. C., \& Scheier, M. F. (1982). Control theory: A useful conceptual framework for personality-social, clinical, and health psychology. Psychological Bulletin, 92, 111-135.

Cross, S., \& Markus, H. (1991). Possible selves across the life span. Human Development, 34, 230-255.

Erikson, E. H. (1968). Identity, youth and crisis. New York: Norton.

Folkman, S., Lazarus, R. S., Pimley, S., \& Novacek, J. (1987). Age differences in stress and coping processes. Psychology and Aging, 2, 171-184.

Gollwitzer, P. M., Heckhausen, H., \& Steller, B. (1990). Deliberative and implemental mind-sets: Cognitive tuning toward congruous thoughts and information. Journal of Personality and Social Psychology, 59, 1119-1127.

Hagestad, G. O. (1990). Social perspectives on the life course. In R. Binstock \& L. George (Eds.), Handbook of aging and the social sciences (3rd ed., pp. 151-168). New York: Academic Press.

Havighurst, R. J. (1953). Human development and education. London: Longmans.

Heckhausen, J. (1997). Developmental regulation across adulthood: Primary and secondary control of age-related challenges. Developmental Psychology, 33, 176-187.

Heckhausen, J. (1999). Developmental regulation in adulthood: Agenormative and sociostructural constraints as adaptive challenges. New York: Cambridge University Press. 
Heckhausen, J. (in press). Adaptation and resilience of midlife. In M. E. Lachman (Ed.), Handbook of midlife development. New York: Wiley.

Heckhausen, J., Dixon, R. A., \& Baltes, P. B. (1989). Gains and losses in development throughout adulthood as perceived by different adult age groups. Developmental Psychology, 25, 109-121.

Heckhausen, J., \& Schulz, R. (1993). Optimisation by selection and compensation: Balancing primary and secondary control in life-span development. International Journal of Behavioral Development, 16, 287-303.

Heckhausen, J., \& Schulz, R. (1995). A life-span theory of control. Psychological Review, 102, 284-304.

Heckhausen, J., \& Schulz, R. (1999). The primacy of primary control is a human universal: A reply to Gould's (1999) critique of the life-span theory of control. Psychological Review, 106, 605-609.

Heckhausen, J., Schulz, R., \& Wrosch, C. (1998). Developmental regulation in adulthood: Optimization in primary and secondary control. Unpublished manuscript, Max Planck Institute for Human Development.

Held, T. (1986). Institutionalization and deinstitutionalization of the life course. Human Development, 29, 157-162.

Jöreskog, K. G., \& Sörbom, D. (1989). Lisrel 7: A guide to the program and applications (2nd ed.). Chicago: SPSS.

Jöreskog, K. G., \& Sörbom, D. (1993). Lisrel 8 user's reference guide. Chicago: SSI.

Kishton, J. M., \& Widaman, K. F. (1994). Unidimensional versus domain representative parceling of questionnaire items: An empirical example. Educational and Psychological Measurement, 54, 757-765.

Lachman, M. E., \& Burack, O. R. (1993). Planning and control processes across the life course: An overview. International Journal of Behavioral Development, 16, 131-145.

Lachman, M. E., \& James, J. B. (1997). Charting the course of midlife development. In M. E. Lachman \& J. B. James (Eds.), Multiple paths of midlife development (pp. 1-17). Chicago: University of Chicago Press.

Lachman, M. E., \& Weaver, S. L. (1998a). The sense of control as a moderator of social class differences in health and well-being. Journal of Personality and Social Psychology, 74, 763-773.

Lachman, M. E., \& Weaver, S. L. (1998b). Sociodemographic variations in the sense of control by domain: Findings from the MacArthur studies of midlife. Psychology and Aging, 13, 553-562.

Lazarus, R. S. (1996). The role of coping in the emotions and how coping changes over the life course. In C. Magai \& S. H. McFadden (Eds.), Handbook of emotion, adult development, and aging (pp. 284-306). San Diego, CA: Academic Press.

Lazarus, R. S., \& Folkman, S. (1984). Stress, appraisal, and coping. New York: Springer.

Lerner, R. M., \& Busch-Rossnagel, A. (Eds.). (1981).' Individuals as producers of their development: A life-span perspective. New York: Academic Press.
Little, T. D. (1997). Mean and covariance structure analyses of crosscultural data: Practical and theoretical issues. Multivariate Behavioral Research, 32, 53-76.

Nurmi, J.-E. (1992). Age differences in adult life goals, concerns, and their temporal extension: A life course approach to future-oriented motivation. International Journal of Behavioral Development, 15, 487-508.

Pearlin, L. I., \& Schooler, C. (1978). The structure of coping. Journal of Health and Social Behavior, 19, 2-21.

Peng, Y. (1993). Primary and secondary control in American and ChineseAmerican adults: Cross-cultural and life-span developmental perspectives. Unpublished dissertation, Brandeis University.

Peng, Y., \& Lachman, M. E. (1994, July). Primary and secondary control: Cross-cultural and life-span developmental perspectives. Paper presented at the 13th Biennial Meeting of Institutional Society for the Study of Behavioural Development, Amsterdam, the Netherlands.

Quayhagen, M., \& Quayhagen, M. P. (1982). Coping with conflict: Measurement of age-related patterns. Research on Aging, 4, 346-377.

Rothbaum, F., Weisz, J. R., \& Snyder, S. S. (1982). Changing the world and changing the self: A two-process model of perceived control. Journal of Personality and Social Psychology, 42, 5-37.

Schulz, R., \& Heckhausen, J. (1996). A life span model of successful aging. American Psychologist, 51, 702-714.

Schulz, R., Heckhausen, J., \& O'Brien, A. T. (1994). Control and the disablement process in the elderly. Journal of Social Behavior and Personality, 9, 139-152.

Schulz, R., \& Rau, M. T. (1985). Social support through the life course. In S. Cohen \& L. Syme (Eds.), Social support and health (pp. 129-149). New York: Academic Press.

Skinner, E. A. (Ed.). (1995). Perceived control, motivation, and coping. Thousand Oaks, CA: Sage.

Sørensen, A. (1990). Unterschiede im Lebenslauf von Frauen und Männern [Life-course differences of men and women]. Kölner Zeitschrift für Soziologie und Sozialpsychologie, Sonderheft 31, 304-321.

Stock, W. A., Okun, M. A., Haring, M. J., \& Witter, R. A. (1983). Age differences in subjective well-being: A meta-analysis. In R. J. Light (Ed.), Evaluation studies: Review annual (Vol. 8, pp. 279-302). Beverly Hills, CA: Sage.

White, R. W. (1959). Motivation reconsidered: The concept of competence. Psychological Review, 66, 297-333.

Wrosch, C., \& Heckhausen, J. (1999). Control processes before and after passing a developmental deadline: Activation and deactivation of intimate relationship goals. Journal of Personality and Social Psychol. ogy, 77, 415-427. 
Appendix

Measurement Instrument for Primary and Secondary Control Strategies (From MIDUS):

Persistence in Goal Striving, Positive Reappraisals, and Lowering Aspirations

Persistence in Goal Striving (Primary Control)

1. When things don't go according to my plans, my motto is, "Where there's a will, there's a way."

2. When faced with a bad situation, I do what I can do to change it for better.

3. Even when I feel I have too much to do, I find a way to get it all done.

4. When I encounter problems, I don't give up until I solve them.

5. I rarely give up on something I am doing, even when things get tough.

\section{Positive Reappraisals (Secondary Control)}

1. I find I usually learn something meaningful from a difficult situation. 2. When I am faced with a bad situation, it helps to find a different way of looking at things.
3. Even when everything seems to be going wrong, I can usually find a bright side to the situation.

4. I can find something positive, even in the worst situations.

\section{Lowering Aspirations (Secondary Control)}

1. When my expectations are not being met, I lower my expectations.

2. To avoid disappointments, I don't set my goals too high.

3. I feel relieved when I let go of some of my responsibilities.

4. I often remind myself that I can't do everything.

5. When I can't get what I want, I assume my goals must be unrealistic.

Received January 12, 1999

Revision received November 2, 1999

Accepted February 21, 2000

\section{New Editors Appointed, 2002-2007}

The Publications and Communications Board of the American Psychological Association announces the appointment of five new editors for 6-year terms beginning in 2002 .

As of January 1, 2001, manuscripts should be directed as follows:

- For Behavioral Neuroscience, submit manuscripts to John F. Disterhoft, PhD, Department of Cell and Molecular Biology, Northwestern University Medical School, 303 E. Chicago Avenue, Chicago, IL 60611-3008.

- For the Journal of Experimental Psychology: Applied, submit manuscripts to Phillip L. Ackerman, PhD, Georgia Institute of Technology, School of Psychology, MC 0170, 274 5th Street, Atlanta, GA 30332-0170.

- For the Journal of Experimental Psychology: General, submit manuscripts to D. Stephen Lindsay, PhD, Department of Psychology, University of Victoria, P.O. Box 3050, Victoria, British Columbia, Canada V8W 3P5.

- For Neuropsychology, submit manuscripts to James T. Becker, PhD, Neuropsychology Research Program, 3501 Forbes Avenue, Suite 830, Pittsburgh, PA 15213.

- For Psychological Methods, submit manuscripts to Stephen G. West, PhD, Department of Psychology, Arizona State University, Tempe, AZ 85287-1104.

Manuscript submission patterns make the precise date of completion of the 2001 volumes uncertain. Current editors, Michela Gallagher, PhD; Raymond S. Nickerson, PhD; Nora S. Newcombe, PhD; Patricia B. Sutker, $\mathrm{PhD}$; and Mark I. Appelbaum, $\mathrm{PhD}$, respectively, will receive and consider manuscripts through December 31, 2000. Should 2001 volumes be completed before that date, manuscripts will be redirected to the new editors for consideration in 2002 volumes. 